\title{
Driving and managing stress in the Deep Mill Level Zone caving mine
}

\author{
K Simanjuntak PT Freeport Indonesia, Indonesia
}

A Primadiansyah PT Freeport Indonesia, Indonesia

N Soumilena PT Freeport Indonesia, Indonesia

W Teweng Golder Associates, Indonesia

\begin{abstract}
The Deep Mill Level Zone (DMLZ) panel cave mine in PT Freeport Indonesia continues to ramp up production since initial undercutting began in 2015. At approximately 1,500 m below surface, the DMLZ is one of the world's deepest caving operations. The current undercut area has reached $60,000 \mathrm{~m}^{2}$, within a 1,200 m triangular-shaped perimeter. This deep mining environment has given rise to substantial pre-mining and induced loading conditions. Stress management in production areas represents the toughest challenge to date for the operation. In addition to applying lessons learned from the overlying Intermediate Ore Zone (IOZ) and Deep Ore Zone (DOZ) mines, extensive empirical ground response data has been collected from undercut and extraction levels. The understanding of how the various geological, geotechnical and mine design criteria interact has resulted in a much-improved approach towards DMLZ stress management. The most notable successes related to DMLZ stress management include improved understanding of ground response, accelerated cave growth, and increased production rates. This paper summarizes the key learnings regarding stress management in production areas and outlines positive improvements undertaken towards sustained, safe caving in the DMLZ.
\end{abstract}

\section{Introduction}

The Deep Mill Level Zone (DMLZ) is part of the Grasberg mine complex located in Papua, Indonesia, operated by PT Freeport Indonesia (PTFI). The DMLZ mine is the fourth lift of caving in the East Ertsberg Skarn System (EESS) and lies $500 \mathrm{~m}$ below the currently producing Deep Ore Zone (DOZ) panel cave mine. The DMLZ is operating at levels 1,500-1,800 m below ground surface (due to varying topography) and set within a strong, brittle, massive to sparsely jointed rock mass. The orebody measures some 1,200 m southeast-northwest by 350-500 m east-west and contains about a half-billion tonnes of ore. There are around 2,450 drawpoints planned, with the scheduled daily tonnage planned to peak at around 80,000 t/d. The mine life is projected through to 2041, and at full production, the DMLZ will have around 700 active drawpoints in operation at any given time (Casten et al. 2016). Figure 1 illustrates the location of the DMLZ mine relative to DOZ, Intermediate Ore Zone (IOZ) and Gunung Bijih Timur (GBT) cave mine sectors.

At the time of writing, undercut blasting has reached an area of $60,000 \mathrm{~m}^{2}$ with 162 drawpoints opened on the extraction level. The strong massive rock substantially constrained the cave back propagation, resulting in a long flat cave back as undercutting advanced. Global preconditioning of the rock mass was implemented, and the propagation rate improved from $200 \mathrm{~mm} / \mathrm{d}$ to $500 \mathrm{~mm} / \mathrm{d}$.

High stress and a seismically active environment represent additional challenges requiring improvements in cave front management, footprint design, monitoring, cave performance and ground support design. In particular, enhancements were made in support design in order to maintain the stability of production 
drifts and to minimize personnel exposure to seismic hazards. This paper presents various geotechnical challenges faced by the mine to establish the new panel caving and implemented strategies to achieve safe, sustainable production targets in a timely manner.

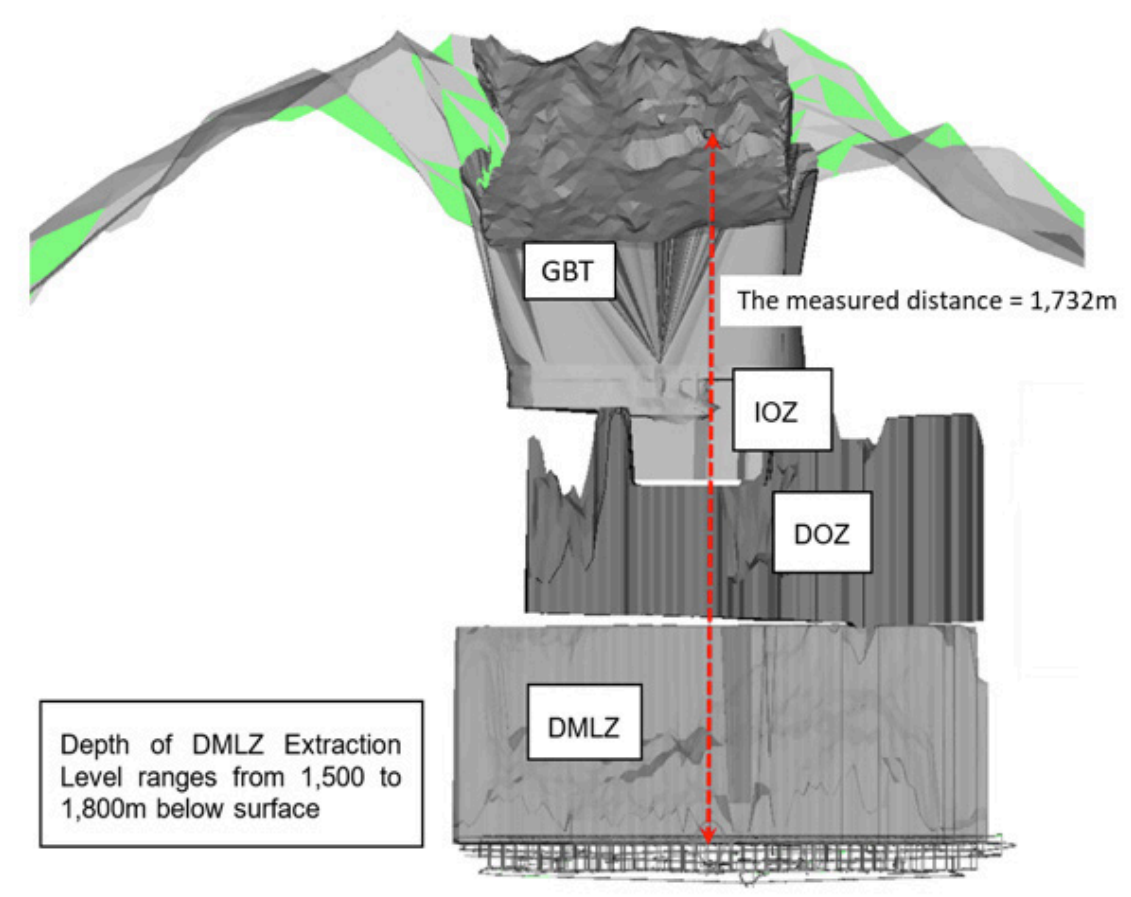

Figure 1 Schematic showing the location of the DMLZ mine relative to DOZ, IOZ and GBT

\section{Geotechnical challenges}

\subsection{Hard and massive rock mass}

Brittle failure behavior generally occurred at hard and massive rock mass in a deep mine. A spalling and strainburst for extreme cases were potentially encountered as experience in DMLZ mine. In terms of caving, the hard and massive rock mass could inhibit cave propagation leading to a requirement of higher cave back stress or preconditioning of the rock mass itself.

The prominent geological domains of the DMLZ include diorite, hornfels and skarn. The diorite is the dominant domain and is competent, massive and includes a limited persistence vein system and widely spaced large scale faulting (which are often healed or partially healed). Table 1 summarizes the representative geotechnical parameters for the DMLZ. However, the recent characterization studies indicated that the diorite is even more massive than the original assessment. Figure 2 illustrates a $9 \mathrm{~m}$ length of recently drilled diorite core at undercut level with no natural fractures and a typical massive diorite at the face heading development.

Table 1 Representative geotechnical rock mass parameter for DMLZ (PTFI 2018)

\begin{tabular}{|c|c|c|c|c|c|c|}
\hline Geotechnical domain & RQD (\%) & FF/m & Jr/Ja & UCS (MPa) & Ei (GPa) & Poisson's ratio, v \\
\hline Te Diorite & 97 & 1.6 & 1.6 & 160 & 53 & 0.29 \\
\hline Hornfels & 91 & 2.9 & 1.5 & 180 & 70 & 0.28 \\
\hline Exoskarn & 92 & 2.4 & 1.6 & 135 & 68 & 0.25 \\
\hline Tw Marble & 83 & 3.8 & 1.5 & 95 & 46 & 0.26 \\
\hline
\end{tabular}




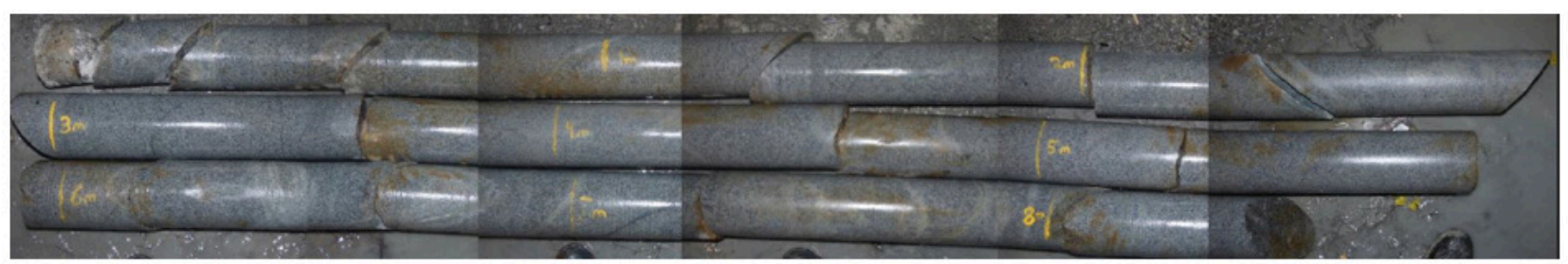

(a)

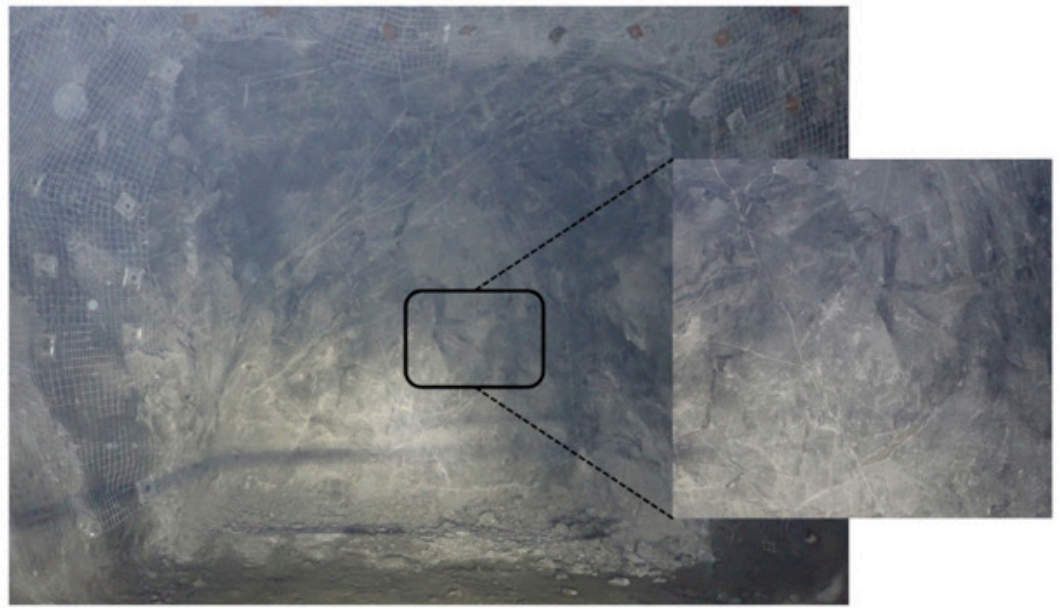

(b)

Figure 2 (a) A $9 \mathrm{~m}$ long diorite drill core lacking natural fractures and (b) typical massive diorite at the face heading of a development drift

\subsection{A large panel caving mine}

The DMLZ footprint area was designed to be 350-500 m wide, 1,200 m long with 42 panel drives, 61 grizzlies, and 2,450 drawpoints. The total proposed undercut area is $480,000 \mathrm{~m}^{2}$. Managing this scale of cave in a high-stress environment required a very good understanding of rock mass response to mining. Cave front management is essential in order to create favourable induced stress distributions and ensure efficient operational sequences. Table 2 presents selected DMLZ mine design parameters.

\section{Table 2 Mine design parameters of the DMLZ}

\begin{tabular}{|c|c|}
\hline Constraint & Design \\
\hline Extraction drift & $4.4 \mathrm{~m}$ width $\times 4.0 \mathrm{~m}$ height \\
\hline Undercut drift & $4.2 \mathrm{~m}$ width $\times 4.0 \mathrm{~m}$ height \\
\hline Distance to adjacent panel & $30 \mathrm{~m}$ \\
\hline Distance to adjacent drawpoint & $20 \mathrm{~m}$ \\
\hline Distance to adjacent drill drive & $15 \mathrm{~m}$ \\
\hline Sill pillar between undercut and extraction level & $10-15 \mathrm{~m}$ \\
\hline Grizzly chamber & $8.6 \mathrm{~m}$ width $\times 5.6 \mathrm{~m}$ height \\
\hline Footprint area & $350-500 \mathrm{~m} \times 1,200 \mathrm{~m}$ \\
\hline
\end{tabular}




\subsection{Mining at depth}

The most noticeable effect of mining at the depth of DMLZ is the increase in magnitude of in situ stress. Several in situ stress measurements were completed during the early development stages of the DMLZ. The latest stress model is summarized in Table 3. The magnitude is present as a function of depth (z) and valid at a depth of more than $900 \mathrm{~m}$ below surface level.

Undercutting is one of the primary factors contributing to stress changes on the DMLZ footprint. The magnification of stress associated with undercutting and caving progress has led to intense seismicity and significant ground damage. The number of seismic events around the cave has grown as the undercut area and cave volume increased, resulting in more significant stress changes. Figure 3 presents the likely major principal stress condition of induced stress as the undercut is advanced over the extraction level.

Table 3 Principal stress magnitude in Mpa vs. depth in meter (after Golder 2018b)

\begin{tabular}{|c|c|c|c|}
\hline Principal stress & Magnitude by depth & Trend & Plunge \\
\hline Major stress, $\sigma_{1}$ & $5+0.027 z$ to $22+0.027 z$ & $040^{\circ}$ & $22^{\circ}$ \\
\hline Intermediate stress, $\sigma_{2}$ & $0.02 z$ to $0.027 z$ & $215^{\circ}$ & $68^{\circ}$ \\
\hline Minor stress, $\sigma_{3}$ & $0.01 z$ to $0.02 z$ & $309^{\circ}$ & $02^{\circ}$ \\
\hline
\end{tabular}
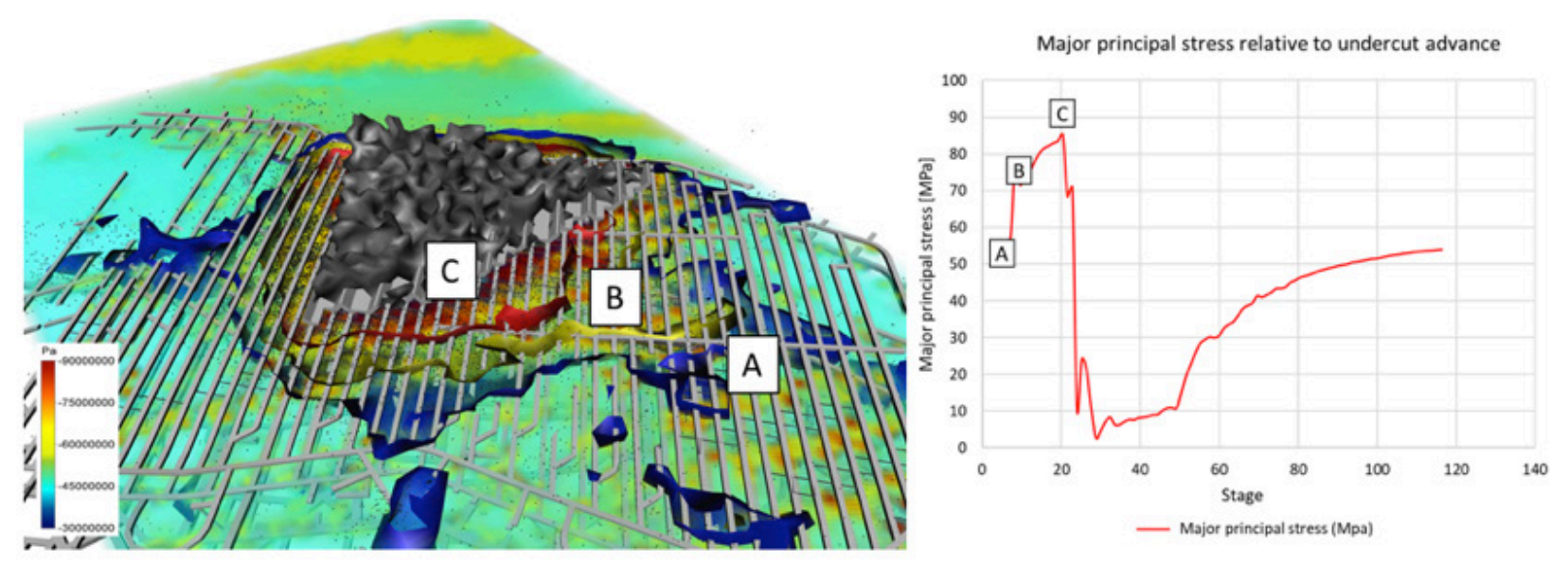

Figure 3 Induced stress magnitudes in the abutment by numerical model output (after Beck Engineering 2019a)

\section{Driving and managing the stress}

Caving is a dynamic process in which production performance changes over time, from the start of the undercutting and extraction level construction through initial production to sustainable caving and finally to mature caving. Currently, DMLZ is considered to be near sustainable caving with the undercut abutment stresses almost at their maximum magnitude.

"The undercut abutment stresses reach the maximum magnitude when the undercut area equates to the required hydraulic radius of the block." Butcher (1999)

Since the early stages of DMLZ PB1 undercutting to date, the abutment area has experienced high caveinduced stresses due to both the size of the undercut (large Hydraulic Radius) and flat cave back due to poor cave propagation. This led to damage of drifts on both the undercut and extraction levels, including extensive bulking, skin damage and strainbursting. The level of damage dictated a change in the overall 
strategy of stress management. Changes included improved cave front management, optimization of extraction ratio (on the extraction level), undercut and draw management, deformation-based ground support design, re-entry protocols to minimize personnel exposure to seismic hazards, and rock mass modification through pre-conditioning which in turn has allowed a better cave shape to be achieved. Figure 4 presents the strategy of stress management in DMLZ with an approach that focuses on how stresses are driven and the consequences are managed.

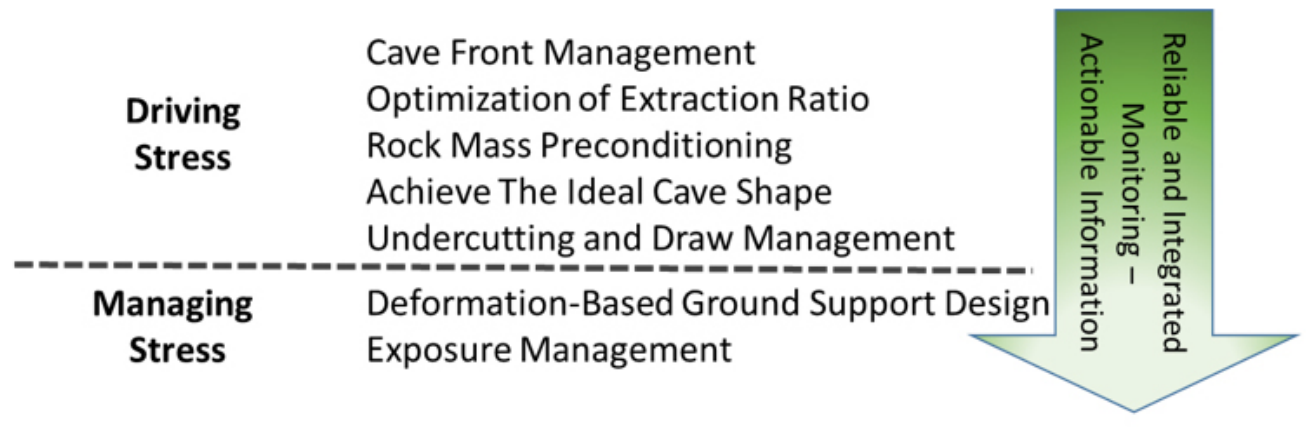

Figure 4 DMLZ approach in managing the stress and ground response

\subsection{Cave front management}

The design of the undercutting sequence for the DMLZ was based on maintaining proper lead lags between adjacent drill drives and an overall undercut angle of $\sim 45$ degrees. The intent of this design was to minimize stress concentrations along the front and uncertainty of behaviour due to complex overall shapes.

To achieve the design sequence, undercutting was initiated in the northwest of PB1 and advanced diagonally to the southeast. The undercut face length reached $300 \mathrm{~m}$ by October 2016. To maintain such a long cave front requires a considerable operational capacity to minimize the development of significant irregularities in the shape of the cave. Due to previous damage-causing events and decreased drill drive availability in October 2016, the undercut had deviated from the design and was comprised of two concave sections.

Figure 5 illustrates the irregular cave front and associated convergence reading. The concave shape resulted in stress concentrations at the front that were evident in accelerated convergence rates associated with fracturing and bulking of the rock mass that comprised the undercut and extraction pillars.

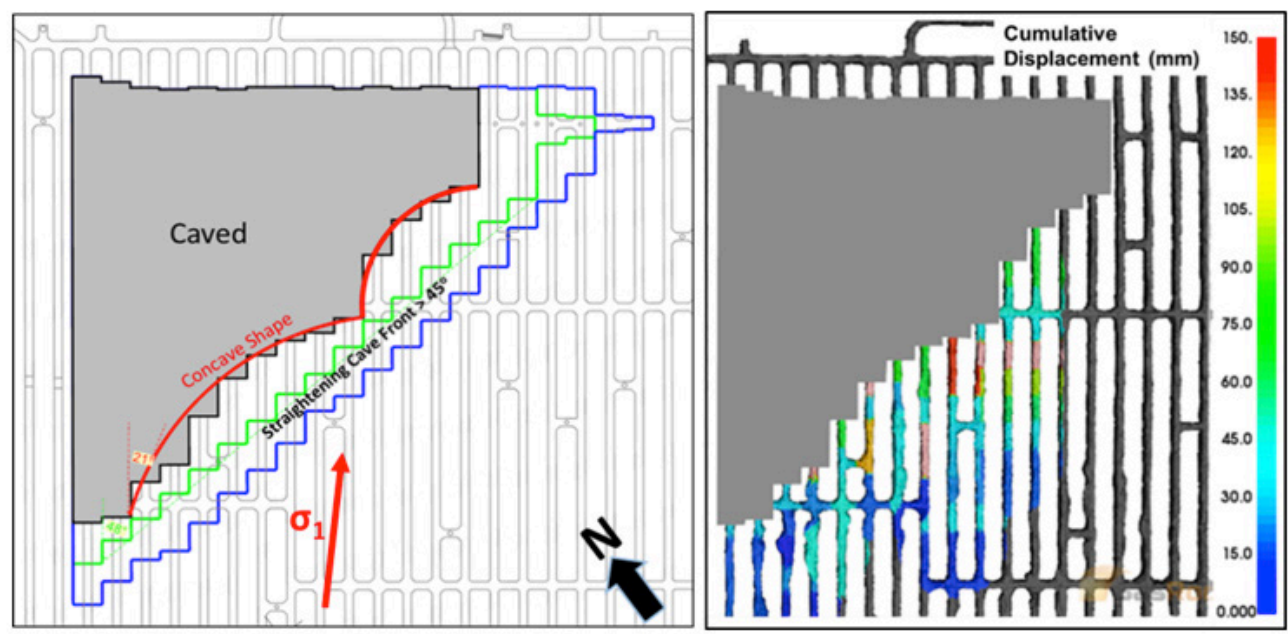

Figure 5 Irregular cave front (left) and convergence (right) reading located close to the concave area 
After October 2016, the undercut cave front was straightened to the desired cave front angle of $45^{\circ}$. This has delivered more favourable stress distribution. The Cave Management Plan (CMP) was re-socialized to ensure a better understanding of the drivers of damage (e.g. prevent concave cave fronts in the future). Table 4 presents the selected portions of the DMLZ CMP associated with cave front management.

Table 4 DMLZ CMP that correlated to cave front management

\begin{tabular}{|c|c|c|c|}
\hline Parameter & Target & Minimum & Maximum \\
\hline Average Lead/Lag & $13 \mathrm{~m}$ & $7 \mathrm{~m}$ & $20 \mathrm{~m}$ \\
\hline Instantaneous Lead/Lag & $13 \mathrm{~m}$ & $4.5 \mathrm{~m}$ & $26.5 \mathrm{~m}$ \\
\hline Lead/Lag Variation for Adjacent Drives & $\pm 1 \mathrm{ring}$ & - & \pm 3 rings \\
\hline Undercut Length/Face Length & $250 \mathrm{~m}$ & - & $300 \mathrm{~m}$ \\
\hline Veranda Length & $40 \mathrm{~m}$ & $20 \mathrm{~m}$ & $50 \mathrm{~m}$ \\
\hline Undercut Face Angle & $41^{\circ}$ & $36^{\circ}$ & $45^{\circ}$ \\
\hline
\end{tabular}

\subsection{Optimization of extraction ratio}

Increased extraction ratios ahead of and within the abutment zone of a cave expose the remaining ground to higher loads and reduced confinement. As a result, these areas are more vulnerable to rock mass damage that manifests as bulking and burst prone areas with elevated abutment stresses. Common areas in the extraction and undercut levels with high extraction ratios are cross-cutting mid access drives used to aid construction on the undercut level, drawpoint turn-outs on the extraction level, and areas with thin sill pillars between undercut and extraction footprints.

Figure 6 illustrates a numerical model that compares the major principal stress concentrations between the stubs (ahead of undercut) and the deferred stub geometry. As observed repeatedly in PB1, high stress concentrates on bullnoses and camelbacks of the intersection led to progressive bulking and elevated strain burst risk. Relative to PB1, a number of improvements were made to development design and sequencing for PB2 and other future production blocks. The improvements included:

\section{No drawpoint turn-outs prior to undercutting}

2. No lateral drifts in undercut level to avoid intersections

3. Increasing the undercut sill pillar thickness to between $14 \mathrm{~m}$ and $16 \mathrm{~m}$

4. And the introduction of $W$-undercut to the remainder of the production blocks.

\subsection{Rock mass preconditioning}

Strong and massive rock masses require a large hydraulic radius (HR) to induce caving. In the case of DMLZ, operational challenges and seismic hazards associated with such a large HR necessitate the use of rock mass preconditioning to promote cave propagation.

In the DMLZ, preconditioning of the rock mass using hydraulic fracturing (HF) commenced in September 2018, targeting the area above the cave back. The intent of the initial HF campaign was to increase cave propagation rates and assist in the growth of the cave. Long down holes between 450-550 m were drilled from the DOZ mine level above the DMLZ cave, while shorter up holes between 125-175 $\mathrm{m}$ were drilled from DMLZ undercut. The spacing between hydraulically induced fractures along the long axis of the hole is $2.5 \mathrm{~m}$ and fractures are predicted to achieve a $30 \mathrm{~m}$ radius. Precondition blasting has been considered to be combined with hydraulic fracturing. At the time this paper was written, the precondition blasting was in preparation and testing phase. Figure 7 presents the schematic of rock mass preconditioning in the DMLZ mine. 

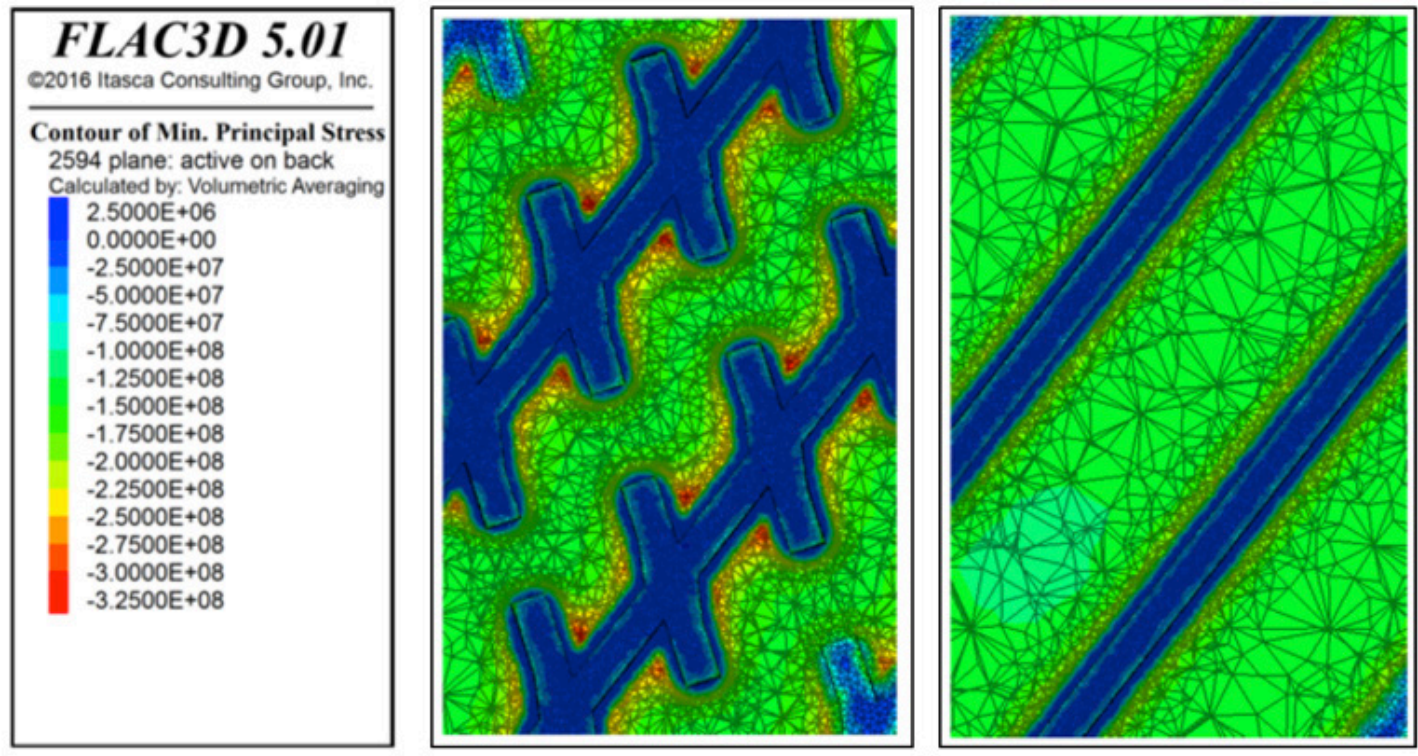

Figure 6 Numerical model illustrating stress concentration between the stubs and deferred stubs geometry (after Golder 2018a; sigma 1 showed by minimum principal stress in the FLAC3D

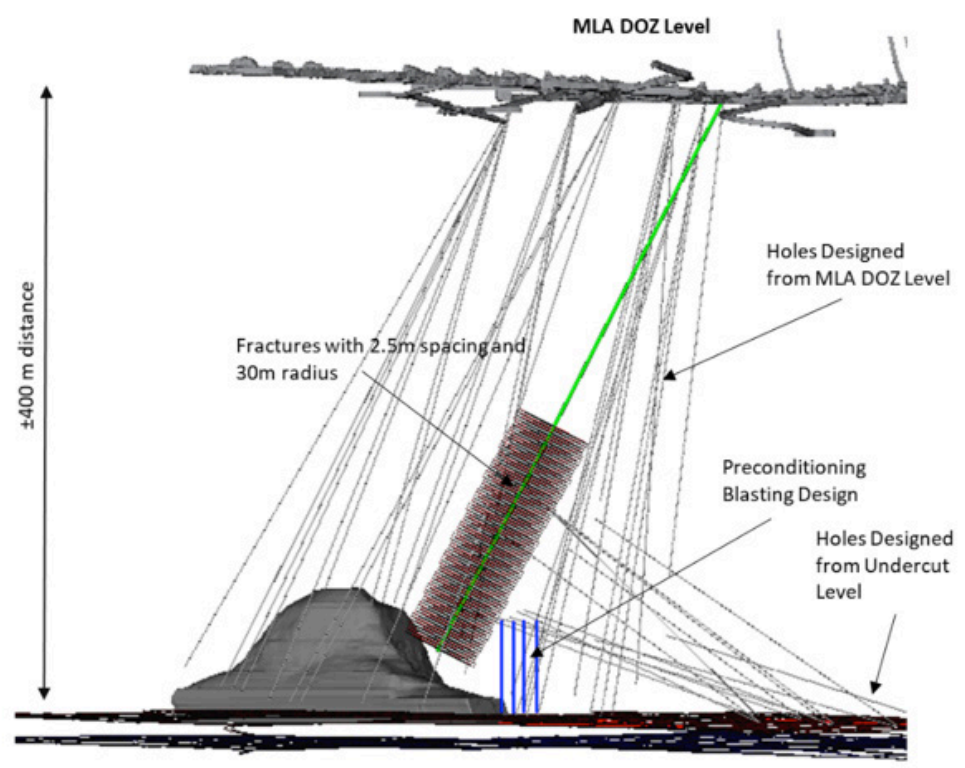

Figure 7 Generalized design of rock mass preconditioning in DMLZ

Preconditioning has shown significant increases in the cave back propagation rate; changing from 200 $\mathrm{mm} / \mathrm{d}$ to $500 \mathrm{~mm} / \mathrm{d}$ with a total vertical propagation of $100 \mathrm{~m}$ in six months at the cave crown (see Table 5). This has positively impacted performance with a 300 percent increase in production rate from $4,000 \mathrm{t} / \mathrm{d}$ to $13,000 \mathrm{t} / \mathrm{d}$. Table 5 presents DMLZ cave propagation history after hydraulic fracturing was implemented. The zones divided into cave crown or mature zone, growth zone and veranda as described in figure 8.

Table 5 Cave back rate prior and after hydraulic fracturing implemented

\begin{tabular}{|c|c|c|}
\hline Zone & Cave rate prior to HF $(\mathbf{m m} / \mathbf{d})$ & Cave rate after $\mathbf{H F}(\mathbf{m m} / \mathbf{d})$ \\
\hline Crown & 200 & 500 \\
\hline Growth & 150 & 300 \\
\hline Veranda & 100 & 200 \\
\hline
\end{tabular}



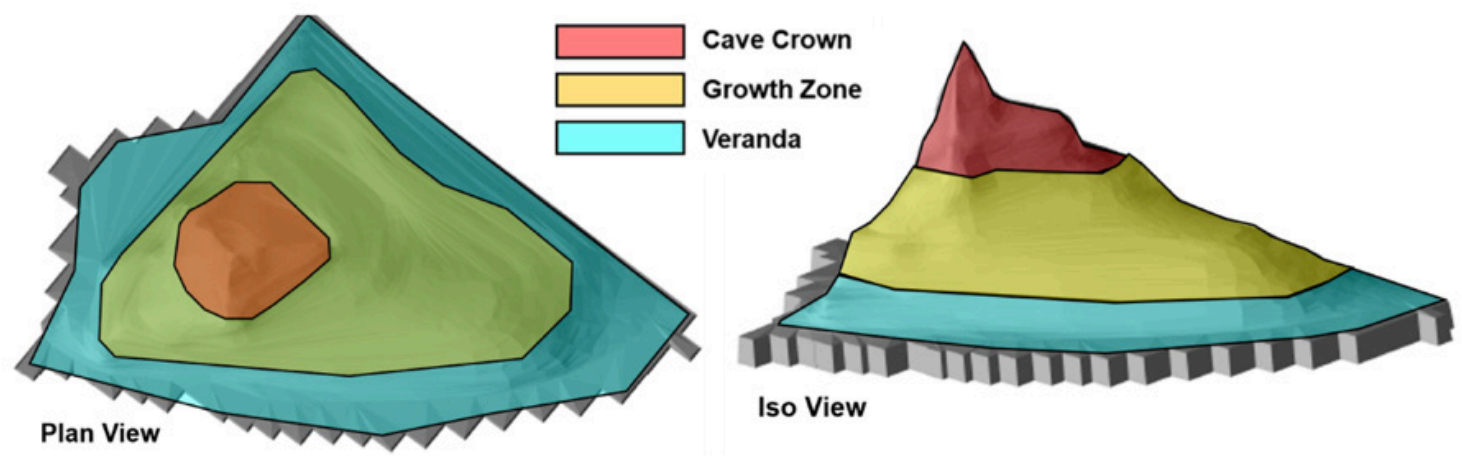

Figure 8 The defined 3 zones in DMLZ cave based on the similarity of the actual cave rate

\subsection{Achieve the ideal cave shape}

The next step after implementing the hydraulic fracturing was to develop an improved cave shape with a minimum $45^{\circ}$ cave back angle. Low cave back angles $\left(<30^{\circ}\right)$, or flat cave backs, have created a highly stressed arch within the mining front. Due to the rock mass, the cave back yields in large increments will create a significant stress changes on the footprint (Beck Engineering 2019b). Figure 9 illustrates the stress arch above the cave back due to a poor cave shape.

Concentrated and higher draw rate was targeted northeast of the DMLZ cave where the cave angle was lowest. A positive cave back response to higher mucking was obtained with the cave angle achieved the $45^{\circ}$. Figure 10 illustrates the higher extraction rates at the flat veranda region resulting in improved vertical cave growth. Moreover, the abutment seismicity was then identified as the local stress change due to undercutting activity. Figure 11 presents the comparison of seismic iso-contour prior and after hydraulic fracturing.

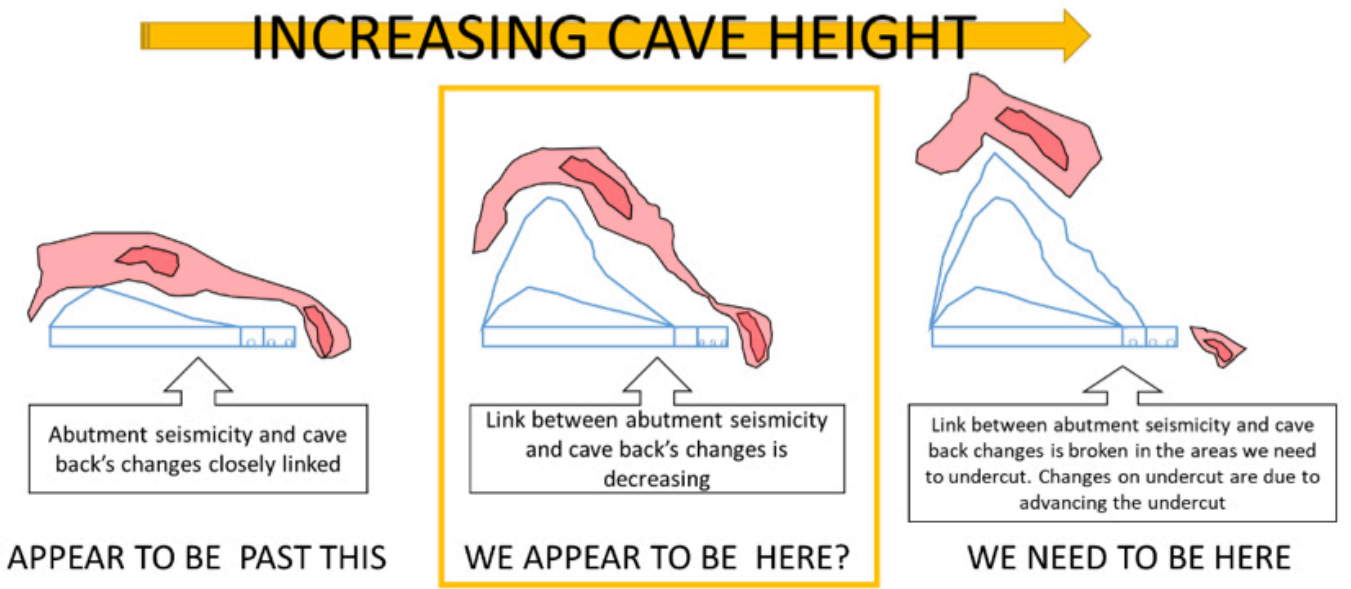

Figure 9 Cave shape condition relative to the seismic arch form due to insufficient caving (after Beck Engineering 2019b) 


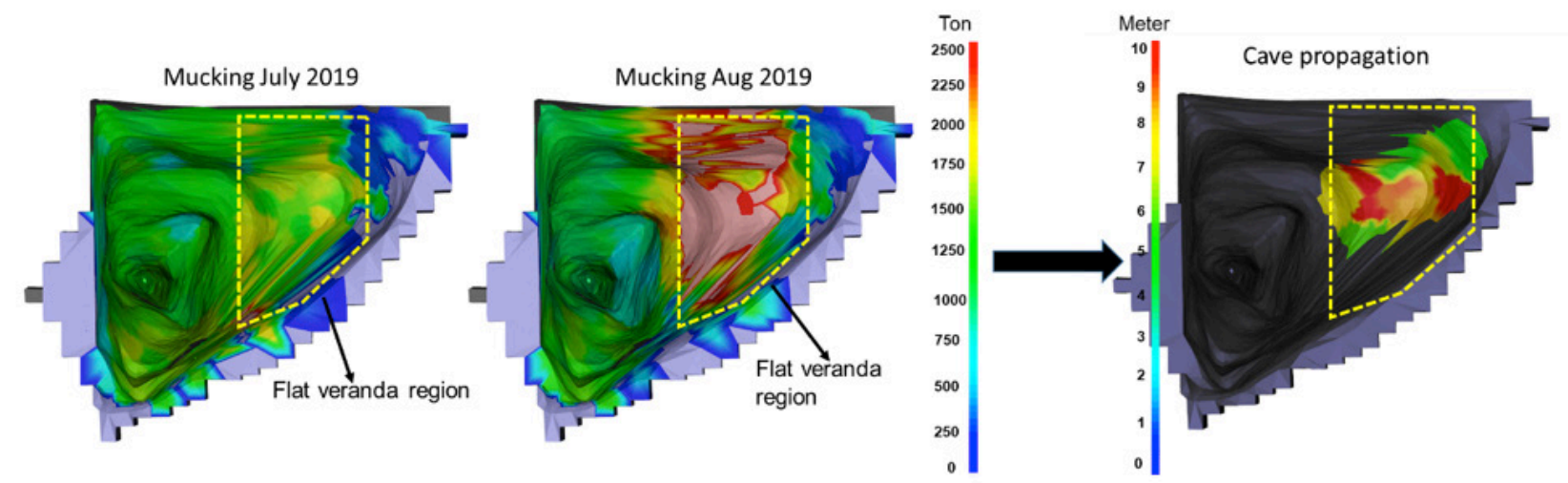

Figure 10 Higher extraction rates in the flat veranda region resulting in improved vertical cave growth
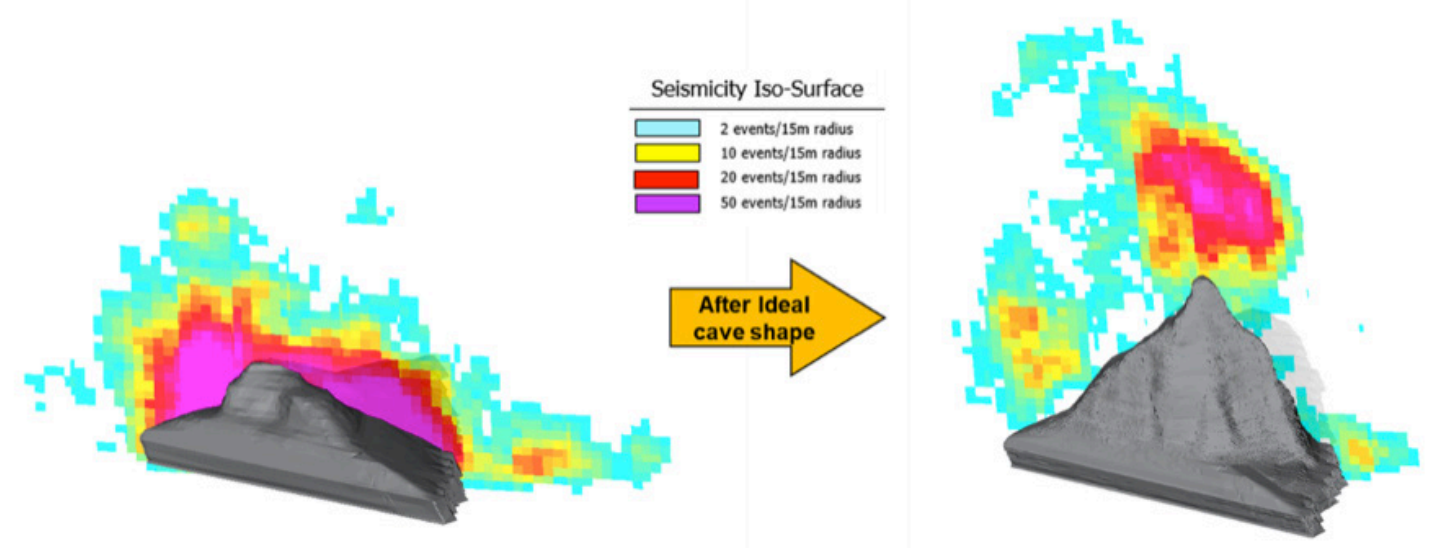

Figure 11 Comparison of seismic iso-contour following vertical cave propagation

\subsection{Undercutting and draw management}

Undercutting and drawing are the main mining activities in caving and are planned to ensure the correct horizontal and vertical growth of the cave. Therefore, the next step is to manage the future undercutting and mucking rates in order to ensure the ideal shape is continually developed. The draw strategy and undercutting sequences during cave propagation should be linked to actual cave back rates and ground response in the abutment.

The DMLZ target is a minimum cave back angle of $45^{\circ}$, thus the vertical growth should be greater or equal to the horizontal growth. Table 5 (above) shows the propagation rate after hydraulic fracturing was implemented. These rates were used to dictate the undercutting and draw rate. Table 6 shows a simulation of undercut and draw rates based on various cave back propagation rates. New draw bell blasting per month is the critical operational limitation. Draw rates were developed with a cave ratio of 2 based on draw rate and cave back propagation data. The cave ratio was generated as ratio between propagation rate and draw rate within a certain period. The cave ratio in DMLZ for each drawpoint show a large range within 1 to 10 based on cave performance until early 2019 (Erhardt et al. 2019).

Table 6 Simulation of undercut and draw rate based on various cave back propagation rate and a cave ratio of 2

\begin{tabular}{|c|c|c|c|c|}
\hline $\begin{array}{c}\text { Cave back } \\
\text { propagation rate }\end{array}$ & $\begin{array}{c}\text { Actual face } \\
\text { length }\end{array}$ & Undercut rate & Drawing rate & $\begin{array}{c}\text { Rate of new draw bell } \\
\text { blasting }\end{array}$ \\
\hline $100 \mathrm{~mm} /$ day & $300 \mathrm{~m}$ & $900 \mathrm{~m}^{2} / \mathrm{month}$ & $0.14 \mathrm{t} / \mathrm{d} / \mathrm{m}^{2}$ & 1 to $2 \mathrm{DB} / \mathrm{month}$ \\
\hline $200 \mathrm{~mm} /$ day & $300 \mathrm{~m}$ & $1,800 \mathrm{~m}^{2} / \mathrm{month}$ & $0.28 \mathrm{t} / \mathrm{d} / \mathrm{m}^{2}$ & $3 \mathrm{DB} / \mathrm{month}$ \\
\hline $300 \mathrm{~mm} /$ day & $300 \mathrm{~m}$ & $2,700 \mathrm{~m}^{2} / \mathrm{month}$ & $0.42 \mathrm{t} / \mathrm{d} / \mathrm{m}^{2}$ & 4 to $5 \mathrm{DB} / \mathrm{month}$ \\
\hline $500 \mathrm{~mm} /$ day & $300 \mathrm{~m}$ & $4,500 \mathrm{~m}^{2} / \mathrm{month}$ & $0.7 \mathrm{t} / \mathrm{d} / \mathrm{m}^{2}$ & 7 to $8 \mathrm{DB} / \mathrm{month}$ \\
\hline
\end{tabular}




\subsection{Deformation-based ground support}

Deformation or displacement is a reliable parameter that can measure the ground response to mining and is a key reference for decision-making and planning. As the load from the cave increases, the likelihood of bursting in the abutment area also increases. Thus, it was necessary to maintain sufficient energy, or displacement capacity margins, to survive the impact of any strain burst. A deformation-based design that established the displacement demand and allowed support system component (bolts or cables) with sufficient displacement or yield capacity to be selected. Displacement of a support system is an indicator of its energy capacity, in other words, displacement measurement gives an indicator of consumed displacement and energy capacity (see Figure 12).

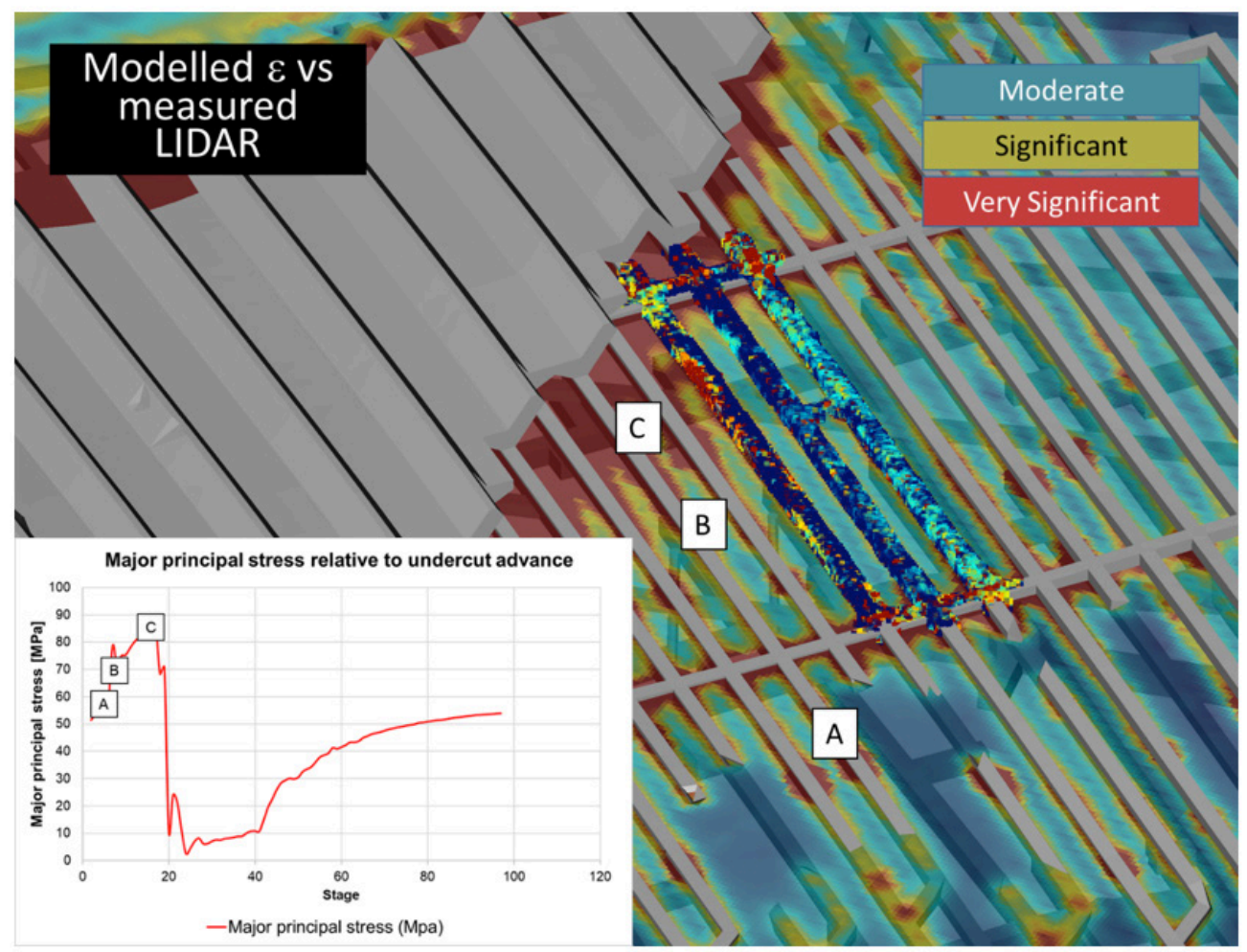

Figure 12 Forecasted strain based on numerical model vs. actual strain from LIDAR result

Maintaining ground support capacity leads to decreasing the amount of support rehabilitation, further reducing or significantly minimizing the strain burst hazard. Based on this concept, DMLZ has adopted a staged ground support approach called Preventive Support Maintenance (PSM). PSM is divided into three stages. Stage 1 monitors the original support capacity. When the measured cumulative displacement reaches $75 \mathrm{~mm}$ (75 percent of initial capacity), then it goes to PSM Stage 2. PSM Stage 2 and 3 adds another $50 \mathrm{~mm}$ of displacement capacity to the system. Stage 3 is required when displacement of the system has reached $125 \mathrm{~mm}$. Finally, rehabilitation will be required when the displacement has reached $200 \mathrm{~m}$. At this point, previous investigations have measured the depth of failure to be more than 2 meters and typically manifests itself as accelerating convergence rates that cannot be maintained with additional surface support. Figure 13 shows the stages of PSM and displacement requirements. Typical PSM support at stage 2 and 3 for the undercut level is a combination of $24 \mathrm{~mm}$ paddle bolts and $17.8 \mathrm{~mm}$ cable bolts and in the extraction level, a combination of $32 \mathrm{~mm}$ threadbar and $17.8 \mathrm{~mm}$ of cable bolts. Figure 14 shows ground support capacity consumption based on displacement monitoring. Convergence tapes, high resolution static scanning and drone scanning are the main tools used to monitor the ground displacement. 

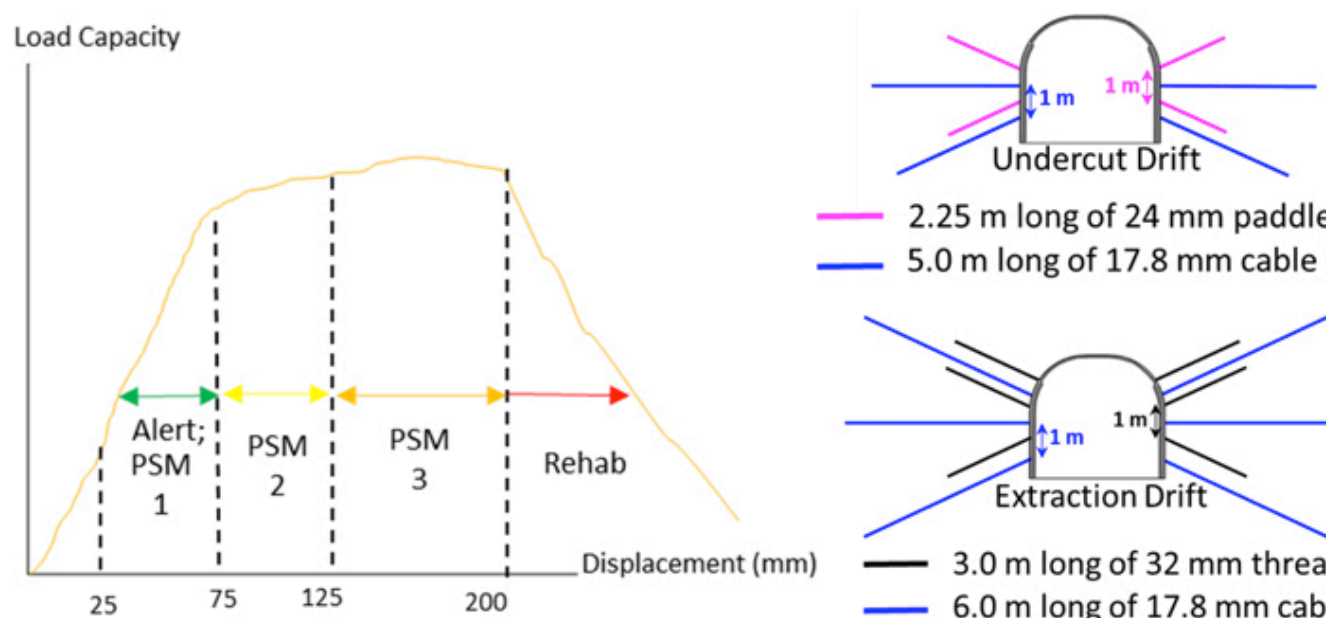

$2.25 \mathrm{~m}$ long of $24 \mathrm{~mm}$ paddle bolt $5.0 \mathrm{~m}$ long of $17.8 \mathrm{~mm}$ cable bolt

Figure 13 Preventive support maintenance (PSM) concept (left) for the DMLZ (modified after Kaiser 2017) and PSM support scheme for stage 2 and 3 (right)
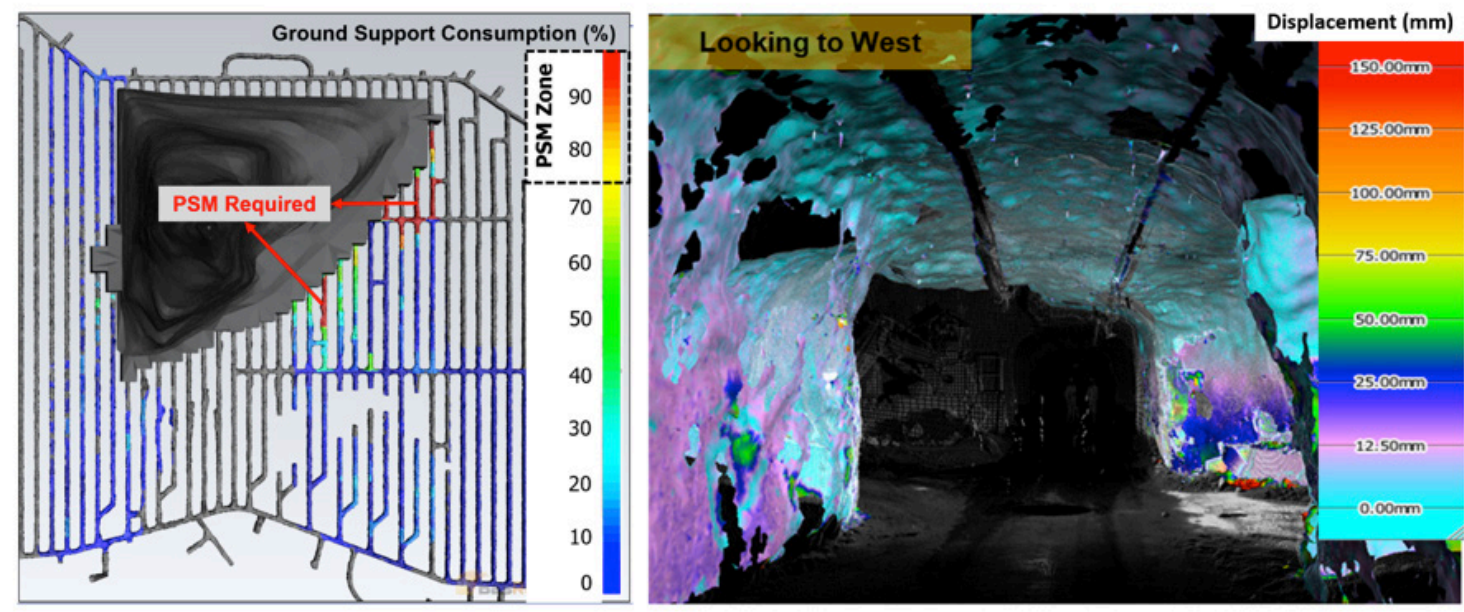

Figure 14 Visualization of ground support capacity consumption through displacement (left) and a result of high-resolution scanning (right)

\subsection{Exposure management}

The most important effort in stress management is to provide procedures to prevent or minimize personnel exposure to seismic hazards. Though the level of stress and seismic hazard has been lowered since the implementation of the revised stress management approach, the remaining hazards need to be anticipated. DMLZ has developed a re-entry protocol by determining the seismic drivers based on empirical data. Four drivers are defined and will activate the protocol once threshold values are exceeded.

The interpretation of convergence, seismic parameters and damage mapping matched to the cave progression are used to identify the exclusion zones (currently divided into three zones). In the early stage of undercutting, the exclusion zone was $60 \mathrm{~m}$ from the cave line; however it continues to increase as the undercut is advanced. Table 7 presents the DMLZ protocol's criteria and the required closure time for each exclusion zone. 
Table 7 DMLZ protocol criteria

\begin{tabular}{|c|c|}
\hline Criteria & Protocol \\
\hline Undercut Blasting & Close blasted area $12 \mathrm{hrs}$; others area close 3 hrs after blasting \\
\hline Event Index $>2$ & Close influenced area; stop hydraulic fracturing activity \\
\hline Significant Event $\mathrm{Mw}>0.7$ & Close influenced area for 2.5 hrs \\
\hline Significant Event Mw $>2.0$ & Evacuate entire mine to surface (portal) \\
\hline
\end{tabular}

\section{Conclusion}

Positive results have been obtained from several improvements in dealing with high stress and very competent rock in the DMLZ panel cave mine. The understanding of the mine environment has continued to evolve since the initiation of development to the present. Favourable stress orientation and stress distribution to influence manageable ground responses to caving progression are the main objectives of this continuous improvement and learning.

All implemented improvements have shown the benefits of using the adopted approach in driving and managing stress for large scale panel caving mines. Based on experience in the DMLZ, the area of improvements should encompass cave front management, extraction ratio, rock mass modification, undercutting-drawing management, ground support and exposure management.

\section{Acknowledgement}

The authors thank PT Freeport Indonesia for permission to publish this paper. Beck Engineering and Golder Associates have provided critical input into the updated DMLZ stress forecast model presented in this paper. Thanks also are extended to Arjuna Ginting, Matt Sullivan, Hendri Silaen, Ryan Campbell, Allan Moss and all co-workers whose comments have improved this paper

\section{References}

Beck Engineering 2019a,'Initial appreciation of the March 2019 to March 2020 draw plan vs recommended strategy', in report DMLZ2019FEB26, Beck Engineering, Sydney, p.5.

Beck Engineering 2019b,'Stress vs. Advance 2019', in report FMI20192019NOV11, Beck Engineering, Sydney, p.4.

Bucher, RJ 1999, 'Design rules for avoiding draw horizon damage in deep level block caves', Journal of The South African Institute of Mining and Metallurgy, SAIMM, vol 1, pp. 151-156.

Casten, T, Golden, R \& Mulyadi, A 2000, 'Excavation Design and Ground Support of the Gyratory Crusher Installation at the DOZ mine, PT Freeport Indonesia', Proceedings of Massmin 2000, Brisbane, 29 October to 2 November 2000.

Erhardt, M, Simanjuntak, K, Primadiansyah, A, Teweng, W, Perez, AB \& Hout, GV 2019, 'Monitoring cave back propagation to inform cave management strategy', Massmin 2020, Santiago, 4-7 October 2020.

Golder Associates 2018a,' DMLZ Flac3D model: model details and calibration', in report 1404134-322-R-Rev0-37000, Golder Associates, Ltd., Vancouver, pp. 22-33.

Golder Associates 2018b,' Review of Grasberg stress measurement and new interpretation', in report 1404134-426-PPRev0-25000, Golder Associates, Ltd., Sudbury, p. 4.

Kaiser, PK 2017, 'Ground control in strainbursting ground - A critical review and path forward on design principles', RaSiM9 2017, Santiago, 15-17 November 2017. 